\title{
CERTIFICAÇÃO FLORESTAL E O MERCADO MOVELEIRO NACIONAL ${ }^{1}$
}

\author{
Ricardo Ribeiro Alves ${ }^{2}$, Laércio Antônio Gonçalves Jacovine ${ }^{3}$, Márcio Lopes da Silva ${ }^{3}$, Sebastião Renato \\ Valverde $^{3}$, José de Castro Silva ${ }^{3}$ e Áurea Maria Brandi Nardelli ${ }^{4}$
}

\begin{abstract}
RESUMO - O objetivo deste trabalho foi avaliar a inserção da certificação florestal no mercado moveleiro nacional. Para a realização deste estudo, utilizaram-se dados do Conselho de Manejo Florestal (FSC Brasil) e dados obtidos por meio de questionários aplicados às empresas moveleiras que possuíam produtos certificados. A certificação mostrou-se presente nas empresas do Estado de São Paulo e da Região Sul, principalmente entre aquelas ligadas à exportação. As empresas da indústria moveleira voltadas para o mercado interno não demonstraram maior interesse na certificação florestal em função da baixa exigência dos clientes.
\end{abstract}

Palavras-chave: Cadeia de custódia, exportação e FSC.

\section{FOREST CERTIFICATION AND FURNITURE NATIONAL MARKET}

\begin{abstract}
The objective of this work was to evaluate the insertion of forest certification in the national furniture market. The data used for the accomplishment of the present study came from the Forest Stewardship Council (FSC Brazil) and the questionnaires applied to the furniture companies with certified products. Companies in the State of São Paulo and in the South Region presented certification, mainly the exporting companies. The furniture companies intended to provide the domestic market did not demonstrate great interest in forest certification because customers did not demand it.
\end{abstract}

Keywords: Chain-of-custody, export and FSC.

\section{INTRODUÇÃO}

Nas últimas décadas, a globalização da economia alterou o comportamento do consumidor, tornandoo cada vez mais exigente em relação à qualidade dos produtos e aos possíveis impactos ambientais e sociais negativos, no seu processo produtivo.

A competitividade de uma organização não depende apenas de fatores econômicos, mas também de uma conduta socialmente valorizada, que garanta a sua legitimidade e sobrevivência no contexto ambiental. Tem havido uma corrida das empresas no sentido de assumir posturas socialmente responsáveis (SILVA e BARBOSA, 2002; COUTINHO e SOARES, 2002). Entre essas posturas, pode-se destacar a crescente preocupação com o meio ambiente, saúde e segurança de seus trabalhadores, bem como a sua responsabilidade social e ética perante a comunidade em que se inserem (LEMOS e NASCIMENTO, 1999).

Nardelli e Griffith (2003) argumentaram que são necessárias modificações na estrutura e estratégia das empresas, bem como mudança de valores para que as questões mencionadas anteriormente sejam inseridas no desenvolvimento das atividades rotineiras da empresa.

No setor florestal, as pressões relativas ao meio ambiente são bem nítidas, principalmente em função dos constantes desmatamentos ocorridos no passado,

\footnotetext{
${ }^{1}$ Recebido em 23.09.2007 e aceito para publicação em 24.04.2009.

${ }^{1}$ Pesquisa financiada pela FAPEMIG.

${ }^{2}$ Programa de Pós-Graduação em Ciência Florestal da Universidade Federal de Viçosa (UFV). E-mail: <ricardo.alves@ufv.br>.

${ }_{3}^{3}$ Departamento de Engenharia Florestal da UFV.E-mail: <jacovine@ufv.br>, <marlosil@ufv.br>, <valverde@ufv.br>, <jcastro@ufv.br>.

${ }^{4}$ Doutora em Ciência Florestal, auditora e revisora técnica do Grupo SGS nas áreas de Sustentabilidade e de Mudanças Climáticas.
} 
em várias partes do planeta. Como primeira medida para conter esse avanço, foi efetuado um boicote aos produtos oriundos de florestas tropicais pelos países desenvolvidos. Com o tempo, verificou-se que essa medida não foi eficaz; posteriormente, optou-se por uma estratégia diferente, em que se buscava premiar os empreendimentos que promovessem o "bom manejo", através de práticas ambientalmente corretas, socialmente benéficas e economicamente viáveis. Essas práticas deveriam ser comprovadas através de sua certificação voluntária, atestada por um organismo independente e de credibilidade perante a sociedade, surgindo, assim, a certificação florestal.

Para conseguir atingir o consumidor, a certificação do manejo florestal requer um sistema que garanta a rastreabilidade da origem de um produto, desde a floresta certificada até o consumidor final. Esse tipo de certificação é conhecido como certificação de cadeia de custódia (chain-of-custody-CoC). Para o consumidor final, a certificação florestal constitui uma garantia de que o produto é proveniente de uma floresta ou plantação florestal que foi manejada de acordo com critérios ambientais e sociais. Atender a esses critérios pode se tornar um diferencial de mercado para muitas empresas. Adicionalmente, pode contribuir para o fortalecimento de sua imagem e se tornar um mecanismo para melhorar suas relações com as diversas partes interessadas do seu campo organizacional (NARDELLI, 2001).

Nardelli e Tomé (2002) argumentaram que a opção por um programa de certificação não significa, necessariamente, maiores custos ou redução de lucros, mas uma estratégia que pode ser utilizada para aproveitar todas as oportunidades, aumentando e mantendo a eficiência das organizações. É importante que estas busquem meios que permitam aplicar os esforços e recursos demandados para atender aos padrões da certificação, na consolidação de um sistema que garanta seu melhor desempenho global. Dessa forma, a certificação florestal torna-se importante ferramenta gerencial para as empresas, além de contribuir nas questões sociais e ambientais.

A certificação tem sido aplicada em várias indústrias do setor florestal, destacando-se, entre elas, a moveleira. Alguns estudos sobre a certificação florestal na indústria moveleira já foram realizados. Jacovine et al. (2006a) estudaram os custos do processo de obtenção da certificação nessa indústria, o uso da logomarca FSC e o grau de atendimento, importância e satisfação das empresas moveleiras certificadas. Um estudo sobre a certificação florestal como estratégia de vendas para a indústria moveleira certificada e sua relação com o marketing for realizado por Jacovine et al. (2006b). E um trabalho semelhante foi realizada por Alves et al. (2007) no Polo Moveleiro de Ubá, analisando-se a certificação florestal na visão estratégica e gerencial dos empresários daquela região.

Realizar, desta forma, um estudo que mostre a abrangência e importância que a certificação florestal possui na indústria moveleira nacional passa a ser fundamental, contribuindo para a adesão de outras empresas nesse processo.

Objetivou-se, com este estudo, avaliar a certificação florestal no mercado moveleiro nacional, buscando:

Identificar a localização das empresas moveleiras certificadas;

Avaliar a evolução, ao longo dos anos, da certificação florestal na indústria moveleira nacional;

Identificar os principais mercados e produtos dessas empresas certificadas e

Verificar a percepção dessas empresas com relação à maior inserção da certificação florestal no mercado moveleiro.

\section{MATERIAL E MÉTODOS}

No início da realização deste trabalho existiam, no Brasil, dois sistemas de certificação: o Conselho de Manejo Florestal (Forest Stewardship Council FSC), de iniciativa internacional; e o CERFLOR, de iniciativa nacional. O CERFLOR reúne a Associação Brasileira de Normas Técnicas (ABNT), o Instituto Nacional de Metrologia (INMETRO) e a Sociedade Brasileira de Silvicultura (SBS). Na época, porém, apenas o FSC possuía organizações com produtos certificados. Assim, delimitaram-se as empresas moveleiras nacionais com certificado de cadeia de custódia pelo FSC.

Na época do estudo existiam 169 empresas com produtos certificados de acordo com os requerimentos do FSC. Para se chegar aos números da indústria moveleira, delimitaram-se as empresas cujo produto certificado (escopo da certificação) estivesse relacionado a "móveis". Obteve-se um total de 28 empresas (16,57\%). 
Para a obtenção dos dados desta pesquisa, optouse pela aplicação de um questionário adequado segundo critérios preestabelecidos por auditores e especialistas na área. As respostas foram obtidas através do envio dos questionários por correio postal e eletrônico, bem como por contato telefônico.

Das 28 empresas listadas, 10 foram desconsideradas da pesquisa pelos seguintes motivos:

Duas, por não possuírem mais a certificação florestal e, portanto, não atendiam mais aos critérios adotados pela pesquisa;

Uma, por atuar exclusivamente como prestadora de serviços na área de design e não possuir processo produtivo; e

Sete, por não se conseguir resposta ou qualquer forma de contato, não havendo garantia de sua existência.

Ao final, nove empresas responderam ao questionário, correspondendo a $50 \%$ do total considerado.

Através dos dados disponibilizados pelo Conselho de Manejo Florestal (FSC Brasil), obteve-se a informação referente à localização das empresas moveleiras certificadas no Brasil e à evolução da sua certificação florestal, sendo os dados agrupados por estado e por ano de certificação.

Com relação aos dados referentes às respostas do questionário, utilizou-se a estatística descritiva e esses foram organizados e sistematizados por meio de tabulação, utilizando-se uma planilha eletrônica.

\section{RESULTADOS E DISCUSSÃO}

\subsection{Localização das indústrias moveleiras certificadas no Brasil}

A Região Sul do Brasil, conforme apresentado na Figura 1, concentra o maior número de empresas moveleiras que possuem a certificação de cadeia de custódia para seus produtos - são 15 certificados ou $55,5 \%$ do total. Como essa região é a principal exportadora de móveis do país, infere-se que a certificação florestal é uma exigência de seus clientes externos ou uma estratégia de vendas adotada pelas empresas. Essa inferência está argumentada no fato de que a certificação envolve custos diversos, como custos de preparação interna da empresa, de aquisição de matéria-prima certificada, de auditoria, de uso da logomarca e de manutenção do certificado. Assim, uma empresa somente iria iniciar um empreendimento desta natureza caso houvesse motivação no mercado.

O Estado de Santa Catarina se destaca pelo maior número de empresas com certificados de cadeia de custódia, num total de 11, seguido por São Paulo com seis certificados. Empresas moveleiras de Estados com tradição em fabricação de móveis como Rio Grande do Sul, Minas Gerais e Espírito Santo não têm buscado a certificação florestal. No caso dos dois últimos Estados, esse fato pode estar relacionado com a pouca experiência de seus polos moveleiros com o comércio externo e, paralelamente, com a baixa exigência do mercado interno.

Segundo Gorini (1999), os polos de São Paulo e os da Região Sul são caracterizados como pioneiros do país. A atividade moveleira, nesses polos, foi contemporânea de um contexto industrial embrionário de formação do mercado interno, baseado no trabalho assalariado e no incremento do movimento imigratório. Em relação ao número de certificados de cadeia de custódia, verificou-se que é muito baixo, pois das 16.000 empresas moveleiras existentes no Brasil, segundo a Abimóvel (2005), apenas 27 têm certificação, o que representa $0,17 \%$ do total.

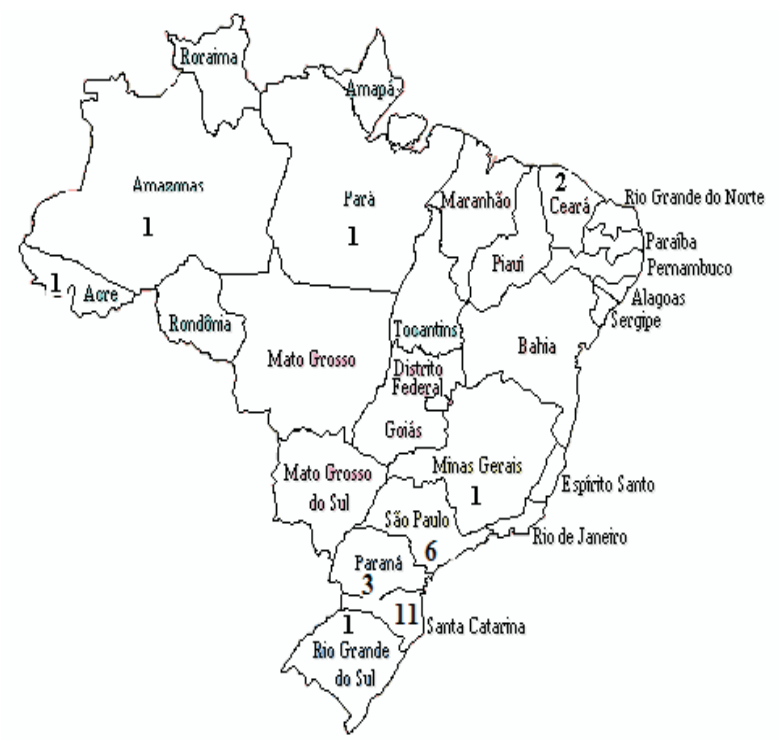

Fonte: Adaptado FSC, 2008. Source: Adapted from FSC, 2008.

Figura 1 - Número de certificados de cadeia de custódia da indústria moveleira nacional, por estado.

Figure 1 -Number of chain-of-custody certificates of the national furniture industry, per state.

R. Árvore, Viçosa-MG, v.33, n.3, p.583-589, 2009 


\subsection{Evolução da certificação florestal na indústria moveleira nacional}

A primeira certificação da cadeia de custódia no Brasil ocorreu em 1996; na indústria moveleira, a certificação somente ocorreu em 1999. Entre as razões para essa "demora" na certificação dessas empresas, pode-se apontar:

A certificação florestal ainda incipiente no país;

A indústria moveleira estava numa transição no uso de suas matérias-primas, passando a adotar, em muitos casos, chapas, compensados e painéis reconstituídos, necessitando, dessa forma, reformular seu processo produtivo; e

Alguns de seus fornecedores ainda não possuíam certificação florestal, elo fundamental na cadeia de custódia. Dois grandes fornecedores da indústria moveleira só obtiveram a certificação florestal em 1996 e em 1998.

Verifica-se, na Figura 2, que nos cinco primeiros anos de certificação florestal (1999-2003) na indústria moveleira apenas cinco empresas se certificaram, representando $18,52 \%$ do total já certificado. Nos três anos subsequentes (2004-2006), já foram sete empresas certificadas $(25,92 \%)$. O maior salto, no entanto, verificou-se nos últimos dois anos (2007-2008), em que 15 empresas $(55,56 \%)$ buscaram a certificação florestal.

Esses resultados apontaram que nos últimos anos as empresas moveleiras têm buscado a certificação florestal de suas unidades e demonstram tendência de crescimento nessa indústria.

\subsection{Principais mercados e produtos das empresas moveleiras certificadas}

De acordo com os resultados, verificou-se que a maior parte das empresas pesquisadas tem suas vendas concentradas no mercado internacional (Figura 3 ). Essa concentração de vendas para o mercado externo está relacionada com a exigência dos clientes desses países, representando nichos de mercado alcançados. Sobre essa questão, Higman et al. (2005) afirmaram que a certificação é vista, muitas vezes, como uma forma de alcançar novos mercados, dispostos a pagar por um produto certificado.

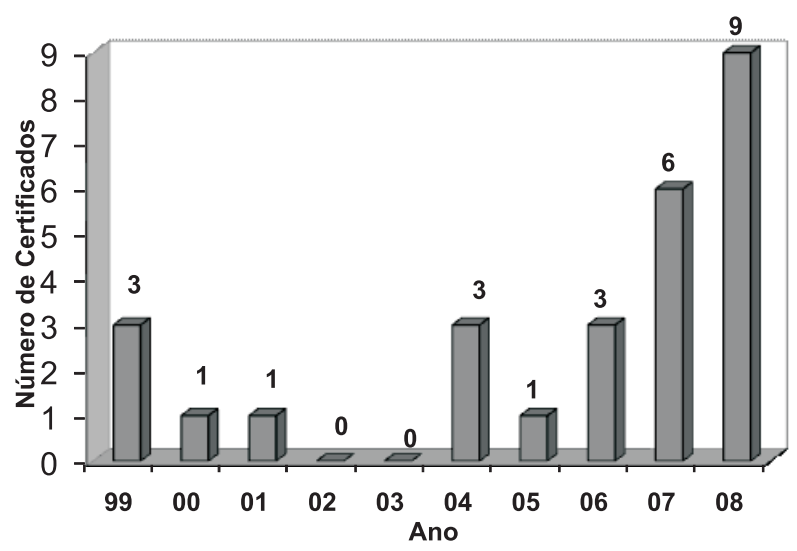

Fonte: Adaptado FSC, 2008. Source: Adapted from FSC, 2008.

Figura 2 - Evolução do número de certificação de cadeia de custódia na indústria moveleira nacional até dezembro 2008.

Figure 2 -Evolution of the number of chain-of-custody certifications in the national furniture industry until December 2008.

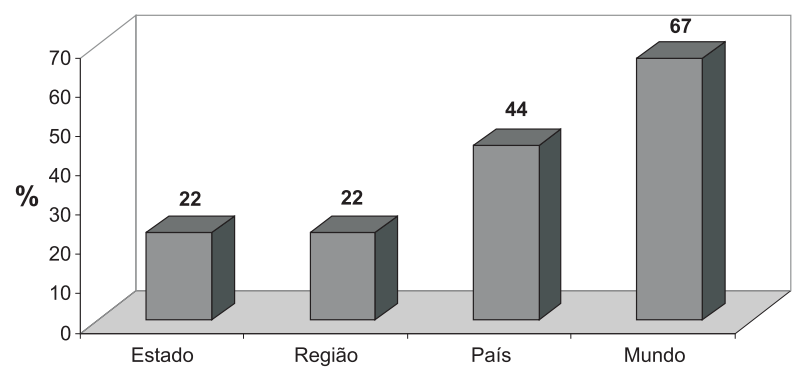

Figura 3 - Destino da produção das empresas de móveis brasileiras que possuem a certificação florestal, em \%

Figure 3 -Destination of the production of the Brazilian furniture companies with forest certification, in \%.

Esse direcionamento de vendas para esse mercado reforça a tese de que a certificação florestal pode-se constituir num diferencial competitivo para as empresas no momento da exportação.

Os principais países importadores de móveis das empresas brasileiras, que possuem certificação, são Estados Unidos, França, Alemanha, Reino Unido, Espanha, Holanda e Argentina (Figura 4). À exceção dos EUA e da Argentina, esses países possuem uma tradicional exigência ambiental. Outros destinos também foram citados, como Japão, Finlândia, Austrália, Israel, Hong Kong, Portugal, Malásia, Nova Zelândia, Colômbia, República Tcheca, Bélgica, Suíça, Itália, Uruguai e México. 


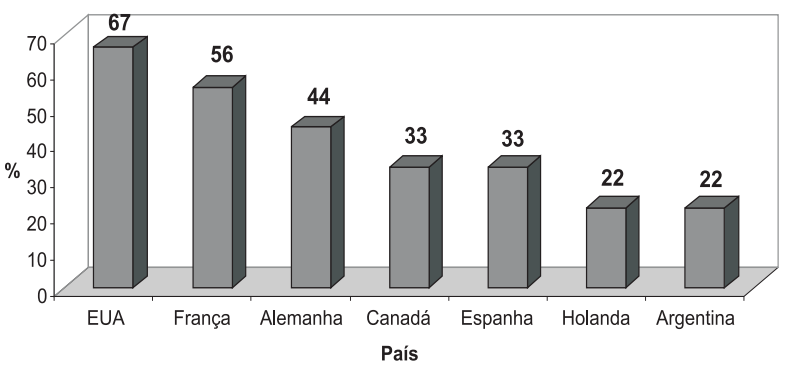

Figura 4 - Destino das exportações dos principais países consumidores de móveis das empresas brasileiras que possuem a certificação florestal, em \%

Figure 4-Destination of the exports for the main countries that consume furniture from Brazilian companies with forest certification, in $\%$.

Verifica-se, também, na Figura 4 que, dos sete principais destinos, seis estão em países desenvolvidos, sendo quatro na Europa. Pode-se afirmar que a certificação florestal constitui mais uma exigência dos mercados de países desenvolvidos do que em desenvolvimento. Com relação a essa exigência, Mazon (1992) ressaltou que, nos países da Europa Ocidental, a rotulagem de produtos indicando aqueles que apresentam menos efeitos adversos para o meio ambiente tem ajudado a guiar a escolha dos consumidores. Segundo Menezzi e Bonduelle (2002), o mercado consumidor internacional passou a exigir, também, a certificação da madeira.

Com relação aos principais tipos de móveis produzidos pelas empresas certificadas, verificou-se que são, basicamente, os da linha de jardim, como bancos, mesas, cadeiras e "espreguiçadeiras", citados por $45 \%$ das empresas. Esse resultado pode significar que parte dos móveis certificados no Brasil é para atender a determinado nicho de mercado, constituído, certamente, por consumidores de alto poder aquisitivo. Outros tipos de móveis citados pelas empresas certificadas (55\%) foram: estantes, gaveteiros, dormitórios, copas, salas de jantar, camas, escrivaninhas, bancos, armários, mesas de centro e cadeiras.

\subsection{A percepção das empresas moveleiras quanto à certificação florestal}

A certificação florestal, segundo $67 \%$ das empresas pesquisadas, representa o principal fator no momento de exportação; as outras $33 \%$ a consideram um fator secundário.

Sendo a certificação florestal fator importante para as empresas, principalmente ligadas à exportação, tornou-se necessário investigar o motivo do baixo número de empresas com esaa certificação. Das empresas pesquisadas, $78 \%$ revelaram que o consumidor ainda não exige a certificação no ato da compra (Figura 5). Esse fator pode desestimular o investimento; se não existe a demanda, dificilmente uma empresa colocaria seu capital em tal empreendimento. O consumidor brasileiro, no geral, ainda desconhece a certificação florestal e não reconhece o selo FSC nos produtos.

Sobre o perfil desse consumidor, Guéron (2003) relatou que a preocupação com a internalização das questões ambientais para o aumento da competitividade é comum nos países desenvolvidos e em estágios de desenvolvimento, havendo diferenças que refletem, principalmente, o grau de conscientização dos consumidores.

Outras razões apontadas para esse baixo número de empresas foram:

- Escassez de matéria-prima certificada, citada por $56 \%$ das empresas. Isso ocorre porque muitos dos fornecedores da indústria moveleira ainda não possuem a certificação de manejo florestal e, ou, de cadeia de custódia dos seus produtos.

- Os empresários ainda não despertaram para a implantação da certificação florestal, de acordo com $44 \%$ das empresas. Alguns fatores podem contribuir para essa situação, como não exigência do mercado, falta de visão gerencial ou, mesmo, desconhecimento da certificação.

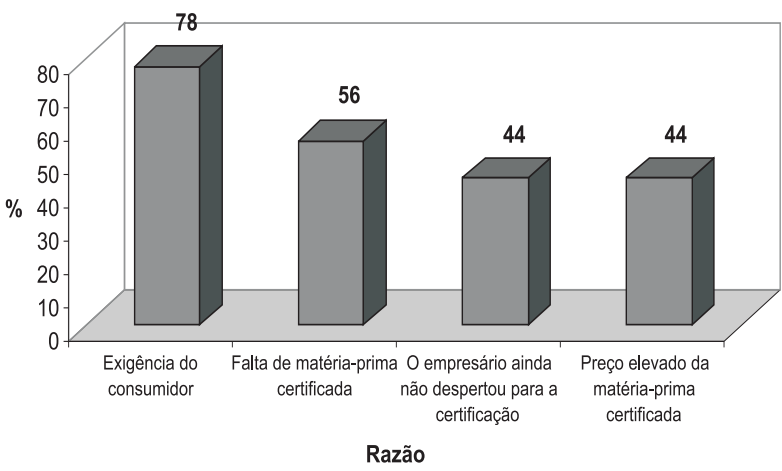

Figura 5 - Principais razões apontadas, pelas empresas certificadas, para o baixo número de empresas com certificação de cadeia de custódia na indústria moveleira, em \%.

Figure 5 - Main reasons found by the certified companies for the low number of companies with chainof-custody certification in the furniture industry, in $\%$.

R. Árvore, Viçosa-MG, v.33, n.3, p.583-589, 2009 
- Preço elevado da matéria-prima certificada, segundo $44 \%$ das empresas.

Algumas afirmações foram feitas pelas empresas pesquisadas: "a grande maioria das indústrias moveleiras exportadoras são constituídas de micro, pequenas e médias empresas, sem condições para conseguir a certificação" e "a existência de mercados fortes, como os Estados Unidos, que normalmente compram mais pelo preço, acima de tudo e que, também, não exigem a certificação florestal". O porte das empresas provavelmente não influencia muito a busca de uma certificação, pois o mais importante é a organização interna da empresa. A certificação encontra resistência a produtos que se destinam ao mercado norte-americano, uma vez que os preços são determinantes nas decisões de compra.

Questionou-se o que poderia ser feito para as empresas moveleiras adotarem a certificação de cadeia de custódia. As respostas foram:

a) Maior divulgação da certificação florestal e de seus benefícios perante a sociedade, atingindo, assim, o consumidor final (44\% das respostas).

b) Maior divulgação da certificação florestal e de seus benefícios entre os empresários moveleiros (33\% das respostas).

c) Decisão gerencial em se optar pela certificação (11\% das respostas).

d) Maior ajuda governamental nos processos envolvendo a certificação florestal (11\% das respostas); uma das empresas mencionou que, em países como África do Sul, Polônia e Suécia, o governo incentivou a implementação da certificação florestal pelas empresas.

Nas empresas moveleiras pesquisadas, ressaltouse a motivação de seu mercado com relação à certificação florestal. Seria necessário motivar o consumidor brasileiro, que não adquire produtos certificados em quantidade semelhante ao que ocorre no mercado externo.

As respostas dadas pelas empresas foram:

a) O consumidor brasileiro, em geral, ainda não se sensibiliza em comprar um produto que internalize preocupação ambiental e social ( $56 \%$ das respostas). Essa percepção do consumidor poderá ser alterada através da educação ambiental, divulgação dos benefícios para a sociedade de produtos ambientalmente corretos e, sobretudo, um preço compatível com seu poder aquisitivo.

R. Árvore, Viçosa-MG, v.33, n.3, p.583-589, 2009

\section{R. Árvore, Viçosa-MG, v.33, n.3, p.583-589, 2009}

b) Geralmente, o produto certificado é mais caro e o consumidor brasileiro ainda não está disposto a pagar o preço (22\% das respostas). Pode-se resolver essa situação com o tempo, à medida que mais produtos forem certificados, promovendo a certificação de mais fornecedores, economias de escala e maior concorrência.

c) A certificação florestal aindaé desconhecida da imensa maioria dos consumidores brasileiros. Há falta de percepção do que seja a certificação (22\% das respostas). Algumas medidas, ainda incipientes, foram adotadas, como a divulgação da certificação florestal em feiras e exposições. No caso moveleiro, os fornecedores certificados ligados a essa atividade poderiam contribuir na divulgação da certificação entre seus clientes. Como atualmente existem poucos desses fornecedores certificados, uma estratégia do próprio fornecedor em se diferenciar de seus concorrentes seria oferecer sua matéria-prima certificada e convencer seu cliente (empresa moveleira) a obter certificação de cadeia de custódia.

\section{CONCLUSÕES}

Pelos resultados apresentados neste trabalho, podese concluir que:

- A certificação florestal na indústria moveleira nacional está concentrada, basicamente, no Estado de São Paulo e na Região Sul do Brasil.

- A certificação florestal está crescendo e atingindo mais empresas da indústria moveleira, em face das exigências cada vez maiores do mercado externo.

- A certificação florestal só não é maior na indústria moveleira em função da baixa exigência dos clientes, principalmente do mercado interno.

- Com o aumento do número de florestas certificadas que vem ocorrendo nos últimos anos, tanto pelo FSC quanto pelo CERFLOR, acredita-se que, aos poucos, haja maior oferta de matéria-prima certificada utilizada pela indústria moveleira.

\section{REFERÊNCIAS}

ASSOCIAÇÃO BRASILEIRA DAS INDÚSTRIAS DO MOBILIÁRIO - ABIMÓVEL Disponível em: <http://www.abimovel.org.br>. Acesso em 23 maio 2005. 
ALVES, R. R. et al. Certificação florestal na visão gerencial e estratégica do Pólo Moveleiro de Ubá, MG. Cerne, v.13, n.1, p.117-122, 2007.

COUTINHO, R. B. G.; SOARES, T. D. L. A. M. Gestão estratégica com responsabilidade social: arcabouço analítico para auxiliar sua implementação nas empresas no Brasil. Revista de Administração Contemporânea, v.6, n.3, p.75-96, 2002.

GORINI, A. P. F. Panorama do setor moveleiro no Brasil, com ênfase na competitividade externa a partir do desenvolvimento da cadeia industrial de produtos sólidos de madeira. São Paulo: BNDES, 1999. 48p.

\section{GUÉRON, A. L. Rotulagem e certificação} ambiental: uma base para subsidiar a análise da certificação florestal no Brasil. 2003. $101 \mathrm{f}$. Dissertação (Mestrado em Ciências em Planejamento Estratégico) - Universidade Federal do Rio de Janeiro, Rio de Janeiro, 2003.

HIGMAN, S. et al. The sustainable forestry handbook. London: Earthscan, 2005. 332p.

JACOVINE, L. A. G. et al. Processo de implementação da certificação florestal nas empresas moveleiras nacionais. Revista Árvore, v.30, n.6, p. 961-968, 2006a.

JACOVINE, L. A. G. et al. Certificação florestal na visão gerencial e estratégica da indústria moveleira nacional. Revista

Semina - Ciências Agrárias, v.27, n.3, p.363-374, 2006b.
LEMOS, A. D.; NASCIMENTO, L. F. A produção mais limpa como geradora de inovação e competitividade. Revista de Administração Contemporânea, v.3, n.1, p.23-46, 1999.

MAZON, R. Em direção a um novo paradigma de gestão ambiental - tecnologias limpas ou prevenção da poluição. Revista de Administração de Empresas, v.32, n.2, p.78-98, 1992.

MENEZZI, C. H. S. D.; BONDUELLE, G. M. Diagnóstico do controle de qualidade na indústria da madeira e do mobiliário no Distrito Federal. Revista Floresta, p.76-86, 2002. Edição Especial.

NARDELLI, A. M. B. Sistemas de certificação e visão de sustentabilidade no setor florestal brasileiro. 2001. 136F. Tese (Doutorado em Ciência Florestal) Universidade Federal de Viçosa, Viçosa, MG, 2001.

NARDELLI, A. M. B.; GRIFFITH, J. J.

Mapeamento conceitual da visão de sustentabilidade de diferentes atores do setor florestal brasileiro. Revista Árvore, v.27, n.2, p.241-256, 2003.

NARDELLI, A. M. B.; TOMÉ, M. V. D. F. Efeito multiplicador dos benefícios da certificação florestal. Revista Floresta, p.94-98, 2002. Edição Especial.

SILVA, C. L. M.; BARBOSA, S. L. Estratégia, fatores de competitividade e contexto de referência das organizações: uma análise arquetípica. Revista de Administração Contemporânea, v.6, n.3, p.7-32, 2002. 
